\title{
Modulation of CGRP-Induced Light Aversion in Wild-Type Mice by a $5-\mathrm{HT}_{1 \mathrm{~B} / \mathrm{D}}$ Agonist
}

\author{
Eric A. Kaiser, ${ }^{1}$ Adisa Kuburas, ${ }^{1}$ Ana Recober, ${ }^{2}$ and Andrew F. Russo ${ }^{1,2,3}$ \\ ${ }^{1}$ Department of Molecular Physiology and Biophysics and ${ }^{2}$ Department of Neurology, University of Iowa, Iowa City, Iowa 52242, and ${ }^{3}$ Veterans Affairs \\ Medical Center, Iowa City, Iowa 52246
}

The neuropeptide calcitonin gene-related peptide (CGRP) plays a critical role in the pathophysiology of migraine. We have focused on the role of CGRP in photophobia, which is a common migraine symptom. We previously used an operant-based assay to show that CGRPsensitized transgenic (nestin/hRAMP1), but not control, mice exhibited light aversion in response to an intracerebroventricular CGRP injection. A key question was whether the transgenic phenotype was due to overexpression of the CGRP receptor at endogenous or novel expression sites. We reasoned that if endogenous receptor sites were sufficient for light-aversive behavior, then wild-type mice should also show the phenotype when given a sufficiently strong stimulus. In this study, we report that mice with normal levels of endogenous CGRP receptors demonstrate light avoidance following CGRP administration. This phenotype required the combination of two factors: higher light intensity and habituation to the testing chamber. Control tests confirmed that light aversion was dependent on coincident exposure to CGRP and light and cannot be fully explained by increased anxiety. Furthermore, CGRP reduced locomotion only in the dark, not in the light. Coadministration of rizatriptan, a 5- $\mathrm{HT}_{1 \mathrm{~B} / \mathrm{D}}$ agonist anti-migraine drug, attenuated the effects of exogenous CGRP on light aversion and motility. This suggests that triptans can act by mechanisms that are distinct from inhibition of CGRP release. Thus, we demonstrate that activation of endogenous CGRP receptors is sufficient to elicit light aversion in mice, which can be modulated by a drug commonly used to treat migraine.

\section{Introduction}

Photophobia is described as abnormal sensitivity to normal levels of light leading to headache exacerbation, eye pain, or lightinduced-discomfort (Noseda and Burstein, 2011). Photophobia is reported by $\sim 80-90 \%$ of migraineurs (Rasmussen et al., 1991; Russell et al., 1996). This frequency is significant given the prevalence of migraine, which affects $\sim 6 \%$ men and $17 \%$ women (Lipton et al., 2007). The mechanisms of migraine and photophobia are poorly understood, but involvement of the trigeminal system is generally accepted (Drummond and Woodhouse, 1993; Borsook et al., 2006; Goadsby, 2009; Messlinger, 2009; Noseda and Burstein, 2011).

Calcitonin gene-related peptide (CGRP) is a multifunctional neuromodulator in the trigeminal system (van Rossum et al., 1997; Arulmani et al., 2004; Recober and Russo, 2009; Raddant and Russo, 2011). Clinical studies have directly implicated CGRP in migraine. CGRP levels in serum and saliva are elevated during spontaneous and induced migraine attacks (Cady et al., 2009; Ho

\footnotetext{
Received July 9, 2012; revised Aug. 31, 2012; accepted Sept. 5, 2012.

Author contributions: E.A.K. and A.F.R. designed research; E.A.K. and A.K. performed research; A.R. contributed unpublished reagents/analytic tools; E.A.K. analyzed data; E.A.K. and A.F.R. wrote the paper.

This work was supported by National Institutes of Health Grants NS075599 and F30 NS067887. We thank Brandon Rea and Jared Stewart for their help with experiments, Austin Barclay for help with data processing, Chris Salvatore (Merck) for providing rizatriptan, lowa City VA Center for the Prevention and Treatment of Visual Loss (C6810-C) for providing the light- dark box system, and members of the Russo lab for stimulating discussions. The authors declare no competing financial interests.

Correspondence should be addressed to Andrew F. Russo, University of lowa, Department of Molecular Physiology and Biophysics, 5-432 BSB, 51 Newton Road, lowa City, IA 52242. E-mail: andrew-russo@uiowa.edu.

DOI:10.1523/JNEUROSCI.3265-12.2012

Copyright $\odot 2012$ the authors $\quad 0270-6474 / 12 / 3215439-11 \$ 15.00 / 0$
}

et al., 2010), although this remains controversial (Tfelt-Hansen and Le, 2009). Remarkably, intravenous CGRP administration is sufficient to induce migraine-like headache in migraineurs (Lassen et al., 2002; Hansen et al., 2010). In contrast, CGRP induced only a mild headache in control subjects (Petersen et al., 2005; Hansen et al., 2010), which suggests the possibility that a stronger stimulus might produce a greater response in nonmigraineurs. Finally, selective CGRP receptor antagonists have proven comparable to commonly used triptan anti-migraine drugs in clinical trials (Olesen et al., 2004; Ho et al., 2008).

A connection between CGRP and triptans has been appreciated for nearly 20 years. The triptans are $5-\mathrm{HT}_{1 \mathrm{~B} / \mathrm{D}}$ receptor agonists that act by inducing vasoconstriction and inhibiting release of CGRP and other neuropeptides (Loder, 2010). The sites of triptan actions are not fully elucidated, although they are known to inhibit CGRP release in the trigeminal spinal nucleus (Amrutkar et al., 2012) and can act at other sites in the CNS that may be relevant in migraine (Ahn and Basbaum, 2005). Triptans were first shown to lower CGRP levels coincident with pain relief (Goadsby and Edvinsson, 1993; Juhasz et al., 2005). More recently, a triptan was reported to reverse CGRP-induced vasodilation and headache pain in migraineurs (Asghar et al., 2011).

In this study, we have tested the ability of CGRP to induce light aversion in wild-type (WT) C57BL/6J mice. This strategy builds on our finding that CGRP could induce light aversion in nestin/hRAMP1 mice that overexpress CGRP receptors in the nervous system (Recober et al., 2009, 2010). We reasoned that increased receptors in the nestin/hRAMP1 mice lower the threshold for CGRP-induced light aversion, but whether CGRP was 
acting at normal or ectopic receptor sites was unanswered. We now report that increased light intensity in combination with habituation to the chamber can unmask CGRP-induced light aversion in WT mice, indicating that endogenous CGRP receptors are capable of transducing such behavior. Importantly, this behavior can be blocked by rizatriptan, which both validates the model and provides an insight into triptan actions on light sensitivity.

\section{Materials and Methods}

Animals. C57BL/6J mice (The Jackson Laboratory) were shipped at 9 weeks of age and then acclimated in our animal facilities for a minimum of $7 \mathrm{~d}$ before testing. Male and female mice were tested between 10 and 14 weeks of age. All animals were housed in groups of $2-5$ per cage in standard conditions, on a $12 \mathrm{~h} \mathrm{light/cycle} \mathrm{(on} \mathrm{at} 0500 \mathrm{CST}$, off at 1700 CST), with access to water and food ad libitum. Animal care procedures were approved by the University of Iowa Animal Care and Use Committee and performed in accordance with the standards set by the National Institutes of Health.

Drug preparation. The following quantities of drugs were administered: $0.5 \mathrm{nmol}$ rat $\alpha$-CGRP (Sigma) and/or $25.5 \mathrm{pmol}$ rizatriptan benzoate (MK 0482; Merck). All drugs were diluted in a total volume of 2.0 $\mu l$ with Dulbecco PBS (Hyclone) as the vehicle.

Drug administration. As previously described (Recober et al., 2009, 2010), drugs were administered via intracerebroventricular injection in the right lateral ventricle through the scalp directly with a needle without prior placement of a cannula. The injection site was $1 \mathrm{~mm}$ posterior to bregma and $1 \mathrm{~mm}$ right from the midline. All injections were performed by the same person (A.K.) after a period of training yielding a success rate of $>90 \%$ as demonstrated by injections of dye into the ventricles. Animals were anesthetized with inhaled 3.5\% isoflurane initially in an induction chamber and then with a nose cone to maintain anesthesia during the injection. After administration, animals were allowed to recover for $60 \mathrm{~min}$ in their home cage. A $60 \mathrm{~min}$ recovery time was chosen because of residual effects of anesthesia in pilot studies at $30 \mathrm{~min}$ (data not shown). At $30 \mathrm{~min}$ following exposure to only anesthesia (without injection), mice spent less time in the light compared with their prior exposure without anesthesia. A similar reduction was also seen $30 \mathrm{~min}$ after either a mock injection or vehicle injection (both under anesthesia). Such a reduction was not observed at $60 \mathrm{~min}$ following vehicle injection (see Results).

Injectors were hand-made by inserting a stripped 30 gauge $\times 0.5$ in needle into nonradiopaque polyethylene tubing (inner diameter: 0.38 $\mathrm{mm}$; outer diameter: $1.09 \mathrm{~mm}$ ). A stopper ( $\sim 1 \mathrm{~cm}$ of tubing) was placed over the needle, leaving $\sim 2.5 \mathrm{~mm}$ of the needle bevel uncovered to control the depth of the injection. Injectors were connected to a $10 \mu \mathrm{l} \mathrm{Ham-}$ ilton syringe.

Light-aversion assay. The testing chambers were a Plexiglas open field ( $27 \mathrm{~cm}$ wide $\times 27 \mathrm{~cm}$ deep $\times 20.3 \mathrm{~cm}$ high) containing three sets of 16 beam infrared arrays (two sets of perpendicular beams cross at a height of $1.0 \mathrm{~cm}$ to detect mouse location and locomotion, and the third beam crosses the width of the chamber at a height of $7.3 \mathrm{~cm}$ to detect vertical activity) (Med Associates). The field was divided in two equal-size zones by a dark insert (Med Associates), which is a five-sided, black-colored Plexiglas box with a top, but no floor. The use of infrared light beams allowed tracking in both zones. An opening $(5.2 \mathrm{~cm} \times 6.8 \mathrm{~cm})$ in the dark insert allowed free movement between zones. While the dark insert blocked direct light, some light could still enter through the opening. At $2.7 \times 10^{4}$ lux, light intensities in the dark zone were $\sim 540$ lux immediately inside the opening, 60 lux at the back wall across from the opening, and 15 lux at all four corners. Each testing chamber was located inside a sound-attenuating cubicle ( $56 \mathrm{~cm}$ wide $\times 38 \mathrm{~cm}$ deep $\times 36 \mathrm{~cm}$ high $)$ with a fan for ventilation (Med Associates). A computer using Activity Monitor v6.02 (Med Associates) was used for recording data from the six chambers.

For each chamber, an LED panel was attached to the ceiling of the sound-attenuating cubicle. The LED panel contains 36 collimated $1 \mathrm{~W}$ LEDs (5500 k Daylight White) (LEDwholesalers.com). To control light intensity, each LED panel was connected to a dimmable LED driver (LINEARdrive; eldoLED America) leading to a potential range of light intensity from $3.0 \times 10^{2}$ to $2.7 \times 10^{4}$ lux. Levels were further attenuated to $5.5 \times 10^{1}$ lux using wax paper placed on a clear Plexiglas tray below the LEDs. Light intensity was measured with Traceable Dual-Display Light Meter (Control Company) placed on the floor of the testing chamber. At $2.7 \times 10^{4}$ lux, LED lights generated some heat in the sound-attenuating chamber with the dark zone at $\sim 25^{\circ} \mathrm{C}$ and light zone at $\sim 27^{\circ} \mathrm{C}$. The temperatures were within range preferred by mice $\left(26-29^{\circ} \mathrm{C}\right)$ and is unlikely to lead to a preference for one zone based on a previous study (Gaskill et al., 2012).

On the day of the experiment, mice were transported from animal housing and allowed to acclimate to the testing room $\left(\sim 22^{\circ} \mathrm{C}\right)$ for at least $1 \mathrm{~h}$ with standard overhead fluorescent lighting ( $\sim 200$ lux inside the housing cage). Room lights remained on, unless noted otherwise. In addition, all sound-generating equipment were turned on during acclimation and remained on until testing was complete. There was minimal human presence in the room during acclimation. Behavioral testing was performed between 0800 and 1400 CST. Any abnormal physical conditions (e.g., missing eye) were noted.

For the novel testing paradigm, mice with no previous exposure to the light-dark box were acclimated to the room, then administered drug as described above. After recovery, mice were placed in the light zone of the light-dark box and tested for $20 \mathrm{~min}$.

For the repeated testing paradigm, there were four exposures: pretreatments 1 and 2, treatment, and post-treatment. For all exposures, the mice were first acclimated to the room before testing, tested, and returned to animal housing; this was repeated $3 \mathrm{~d}$ later for the next exposure. The exposures were done every $3 \mathrm{~d}$ based on prior studies indicating that while the chamber novelty would be reduced, the mice would still continue to explore the light zone (Bourin and Hascoët, 2003). In pretreatment 1 and 2, mice were placed in the light-dark box and tested for 20 $\mathrm{min}$. In the treatment exposure, mice were administered drug, allowed to recover from anesthesia for $60 \mathrm{~min}$, and then tested for $20 \mathrm{~min}$. In the post-treatment exposure, mice were again tested for $20 \mathrm{~min}$ without any treatment to determine whether the effects were reversible. The standard LED lighting was $2.7 \times 10^{4}$ lux for all four exposures. The exceptions were the two dark control experiments. In the first control, the mice were acclimated and tested in a darkened room with minimal red lighting to aid the experimenter and all other lights off in the room and testing chambers. In the second control, the mice were acclimated and tested in the room with standard lighting conditions for the pretreatment exposures; however, for the last two exposures, mice were acclimated and tested in the darkened room with only red light and all other lights off in the room and testing chambers. When the lights were off, the formerly lit zone was referred to as the uncovered zone, and the zone within the dark insert was referred to as the covered zone. During acclimation and recovery when the lights were off, cages were covered to limit light exposure from opening doors and the room red light.

Motility measurements. Several movement parameters were used to assess the effects of drug administration on locomotion, which is required for exploration in the light-aversion assay. Motility was measured at the same time as light aversion, using the testing chambers, conditions, and software described above. The number of vertical movements, such as rearing, was based on beam crosses at a height of $7.3 \mathrm{~cm}$. Ambulatory distance $(\mathrm{cm})$ was defined as the total distance traveled during ambulatory movement status, which is initiated when the center of the mouse leaves a box defined by three beams $(5.06 \mathrm{~cm})$. Resting time was calculated as the percentage of time spent breaking no new beams. Ambulatory velocity $(\mathrm{cm} / \mathrm{s})$ was calculated by dividing ambulatory distance by ambulatory time, which was defined as time spent in ambulatory movement status. All motility parameters were normalized to the time spent in each zone to account for different amount of time spent in that zone; thus, the raw value for each parameter was divided by the time spent in that zone during the $5 \mathrm{~min}$ interval.

Open field test. An open field test was used to assess center avoidance as a measure of anxiety to determine the contribution of anxiety in the light-aversion assay. Testing was conducted in the same manner as the light-dark box. For the two pretreatment exposures, mice were accli- 


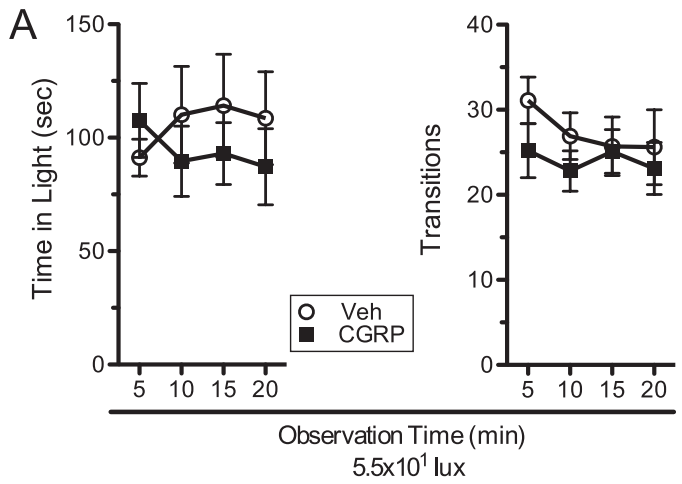

B

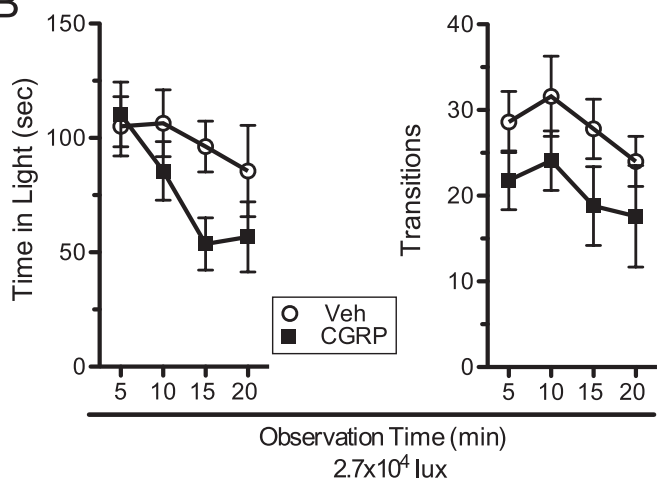

Figure 1. Lack of CGRP-induced light aversion upon naive exposure of WT mice at low and bright light intensities. Time spent in light zone and number of transitions between zones shown on the left and right, respectively. $A$, Behavior in low light $\left(5.5 \times 10^{1}\right.$ lux $)$ after intracerebroventricular injection of $\operatorname{CGRP}(\boldsymbol{\square}, n=10)$ or vehicle (Veh) $(\bigcirc, n=10)$. B, Behavior in bright light $\left(2.7 \times 10^{4}\right.$ lux $)$ after intracerebroventricular injection of CGRP $(\boldsymbol{\square}, n=10)$ or vehicle $(\bigcirc, n=10)$. Observation time indicates the interval over the previous $5 \mathrm{~min}$ (e.g., $5 \mathrm{~min}$ interval is from 0 to $5 \mathrm{~min}$ ). Error bars indicate mean $\pm \mathrm{SEM}$.

mated as described above and exposed to the light-dark box for 20 min, each time at $2.7 \times 10^{4}$ lux. For the treatment and post-treatment exposures, the dark insert was not placed in the chamber, creating an open field at $2.7 \times 10^{4}$ lux. Animals were placed in the center of the open field and tested for $20 \mathrm{~min}$. The periphery was defined as a 4.22 $\mathrm{cm}$ border along the inside wall of the chamber creating a center area of $18.56 \mathrm{~cm} \times 18.56 \mathrm{~cm}$ (software settings: Start X: 2.5; Start Y: 2.5; End X: 14; End Y: 14).

Statistical analysis. The data were first analyzed between treatment groups (e.g., vehicle, CGRP) within each single exposure period (naive, pretreatments 1 and 2, treatment, post-treatment). We used a two-way repeated-measures ANOVA (factors: treatment and observation time); where significant effects were observed, we used Bonferroni's multiplecomparison test for post hoc analysis, comparing treatment groups at each time interval. In rizatriptan experiments, a secondary analysis was conducted for time in light where only CGRP and rizatriptan coadministered with CGRP treatment groups were included instead of all four treatments. This allowed for a more direct comparison between the two groups. For comparing data between $5.5 \times 10^{1}$ lux and $2.7 \times 10^{4}$ lux at a specific interval in naive experiments, unpaired two-tailed Student's $t$ test was used to assess two-sample comparisons. To make comparisons between exposure periods, we compared each treatment group during the treatment exposure to their pretreatment 2 and post-treatment values at each interval. We used a one-way repeated-measures ANOVA (factor: observation time); where significant effects were observed, we used a Bonferroni's multiple-comparison test for post hoc analysis at specific time intervals. Data are reported as mean \pm SEM. Data were analyzed using GraphPad Prism software (GraphPad Software).

Mice were excluded from analysis due to the following reasons: missing eye $(n=1)$ and never leaving the light zone during 20 min of testing $(n=1)$. In addition in Figures 7 and 8, three mice were not included in
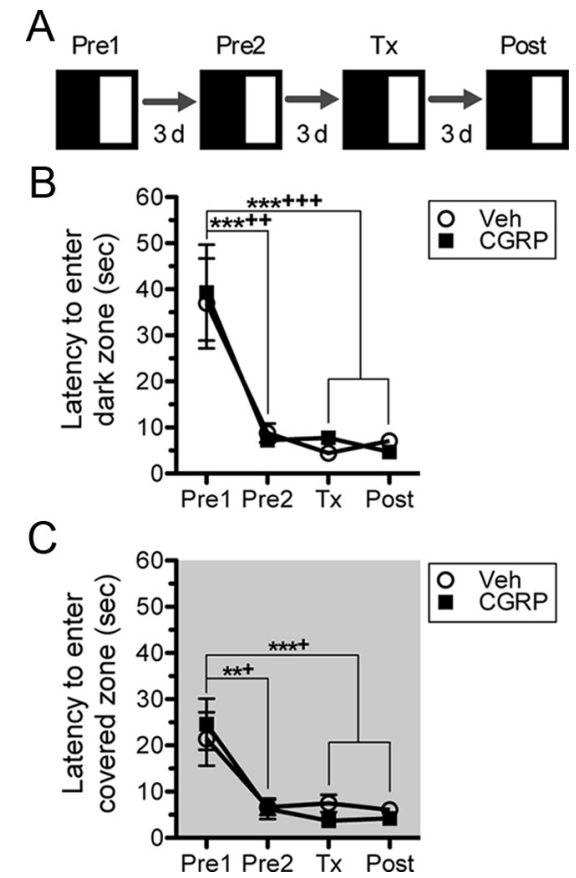

Figure 2. Repeated testing paradigm decreases latency to enter dark or covered zone. $\boldsymbol{A}$ Schematic of repeated testing paradigm in which WT mice were exposed to the light-dark box four separate times: pretreatment 1 (Pre1), pretreatment 2 (Pre2), treatment (Tx), and posttreatment (Post). Each successive exposure occurred on the third day after previous exposure. $\boldsymbol{B}$ Latency to enter the dark zone at $2.7 \times 10^{4}$ lux. Latencies are shown for two cohorts of mice before and following intracerebroventricular injection of vehicle (Veh) $(\bigcirc, n=14) \operatorname{orCGRP}(\square$ $n=20$ ). C, Latency to enter the covered zone with the lights off ( $\sim 0$ lux) for two cohorts of mice before and after injection of vehicle $(O, n=10)$ or $\operatorname{CGRP}(\square, n=10)$. In both $\boldsymbol{B}$ and $\boldsymbol{C}$ vehicle and CGRP-treated mice showed significantly reduced latencies after the first exposure (Veh: ${ }^{+} p<0.05,{ }^{++} p<0.01,{ }^{+++} p<0.001$; CGRP: $\left.{ }^{* *} p<0.01,{ }^{* * *} p<0.001\right)$. Error bars indicate mean \pm SEM.

pretreatment 1 data due to equipment malfunctions leading to mistracking of the animal. In Figure $2 B$, one mouse treated with vehicle was excluded as an outlier as it was $>1.5 \times$ the interquartile range for all four exposures.

\section{Results}

Lack of CGRP-induced light aversion in WT mice in a novel chamber

To study light aversion, we modified the operant light-dark assay previously used with the transgenic nestin/hRAMP1 mice (Recober et al., 2010). In this assay, there is a balance between exploration of a novel environment and a preference for the dark compared with the light (Bourin and Hascoët, 2003). We have defined CGRP-induced light aversion as increased avoidance of the light following CGRP administration. In this paradigm, the mice are presumed to escape the light due to CGRP-mediated exacerbation of an aversive condition. After placement in the chamber, each mouse was tracked by infrared array for $20 \mathrm{~min}$ divided into four $5 \mathrm{~min}$ intervals. This longer tracking allowed for observation beyond the initial exploratory period that generally occurs in the first $5 \mathrm{~min}$ (Crawley, 2008). In place of dim incandescent bulbs, a full spectrum, adjustable LED light source was used. Mice were administered intracerebroventricular CGRP or vehicle $60 \mathrm{~min}$ instead of $30 \mathrm{~min}$ before behavior testing. This longer recovery time was chosen to minimize residual effects of anesthesia and optimize the difference between the effects of CGRP and vehicle based on testing at 30, 90, 120, and $240 \mathrm{~min}$ postinjection (data not shown). 
To determine the effects of CGRP on endogenous CGRP receptors, we selected C57BL/6J mice as the WT strain to study. This strain was chosen, since the previously studied nestin/hRAMP1 mice are predominantly on the C57BL/6J background (Recober et al., 2009, 2010). As predicted at a dim light level of $5.5 \times 10^{1}$ lux, WT mice treated with CGRP or vehicle spent a similar amount of time in the light across all four 5 min intervals; moreover, treatment had no effect on time in light (Fig. 1A). Our previous study with nestin/hRAMP1 mice, but not littermate controls, also had decreased transitions and reduced ambulatory distance, time, and rearing following CGRP administration (Recober et al., 2010). In contrast, CGRP did not affect transitions of the WT mice (Fig. $1 A$ ), or the vertical beam breaks, resting time, ambulatory distance, and ambulatory velocity (data not shown). This confirmed that at dim light levels WT mice do not demonstrate any effects of CGRP on time in the light, transitions, or locomotion.

Since C57BL/6J mice, unlike nestin/ hRAMP1 mice, are not sensitized to CGRP, we conjectured that WT mice might require a greater stimulus to induce light avoidance. Light intensity was increased to a bright level of $2.7 \times 10^{4}$ lux, which is approximately equivalent to direct daylight (Ashby et al., 2009). There was no overall effect of treatment on time in the light (Fig. $1 \mathrm{~B}$ ). Furthermore, treatment had no effect on number of transitions between zones at any interval (Fig. $1 B)$. While there was a trend in later intervals for CGRP-treated mice to avoid the light compared with vehicle-treated mice, bright light was insufficient to induce a significant CGRP-induced light aversion.

\section{CGRP-induced light aversion revealed in WT mice by a} combination of bright light and habituation to the chamber Since there was a trend of a greater CGRP effect in the later testing intervals in bright light (Fig. $1 B$ ), we reasoned that a significant CGRP effect might be revealed following prior exposures to the chamber to facilitate habituation to the chamber. By reducing novelty of the environment, it could alter the balance between exploration of the light zone and avoidance of an aversive condition, the light, following CGRP administration. To facilitate habituation, we developed a repeated testing paradigm (see Materials and Methods; Fig. 2A) that built on prior studies with the light-dark box (Bourin and Hascoët, 2003).

Latency to enter the dark zone is predicted to decrease after prior exposure to a light-dark box (Bourin and Hascoët, 2003). Indeed, the latency decreased after the first pretreatment where time had an overall effect $\left(F_{(3,96)}=17.31, p<0.0001\right)$ with no treatment effect (Fig. $2 B$ ). Compared with the first exposure, the latency was significantly less in the remaining three exposures in both the vehicle and CGRP groups $(p<0.01)$. This was also observed when the lights were off for all exposures (Fig. 2C). With lights off, latency to enter the covered zone (dark zone when lights were on) decreased after the first pretreatment where time had an overall effect $\left(F_{(3,54)}=14.87, p<0.0001\right)$ with no treatment effect. Compared with the first exposure, the latency was significantly less in the remaining three exposures in both the vehicle and CGRP groups $(p<0.05)$. Therefore, one pretreatment was sufficient to reduce initial exploration, regardless if the lights were on or off, demonstrating a degree of habituation to the chamber.

The effect of CGRP on avoidance of either dim or bright light following the pretreatments was then tested. Repeated testing in dim light $\left(5.5 \times 10^{1}\right.$ lux $)$ was insufficient to observe a difference in time in light between CGRP- and vehicle-treated mice (data not shown). In contrast, repeated testing in bright light $(2.7 \times$ $10^{4}$ lux) did reveal a difference in time in light between CGRPand vehicle-treated mice (Fig. 3A). CGRP-treated mice spent significantly less time in light than vehicle-treated mice at the 10 and 15 min intervals $(p<0.001)$ with an overall effect of treatment $\left(F_{(1,33)}=14.46 ; p=0.0006\right)$. Furthermore, CGRP-treated mice spent significantly less time in the light compared with the prior pretreatment exposure at 10,15, and 20 min intervals $(p<$ $0.001)$. There was no significant decrease at any interval compared with the prior exposure with vehicle-treated mice. As expected, before treatment, both cohorts of mice spent comparable 


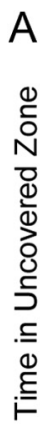

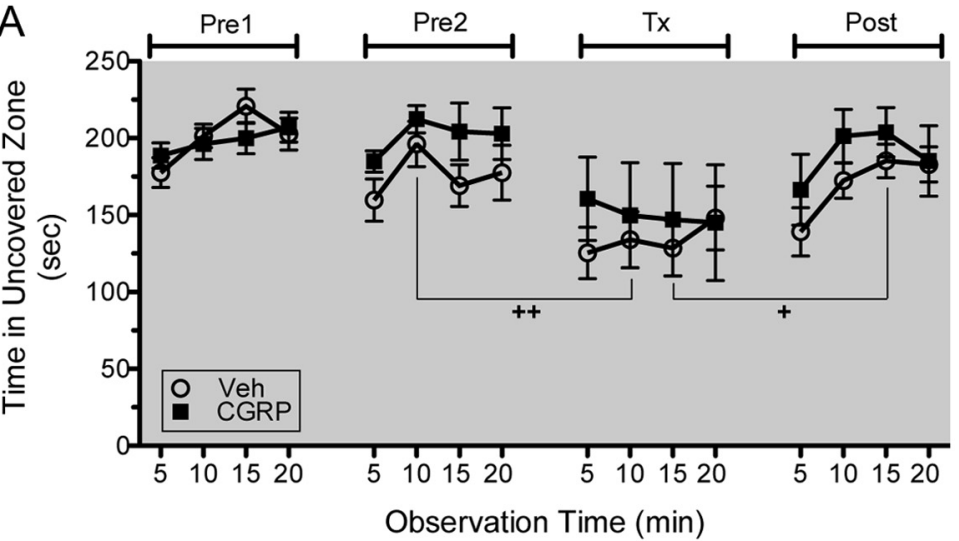

B

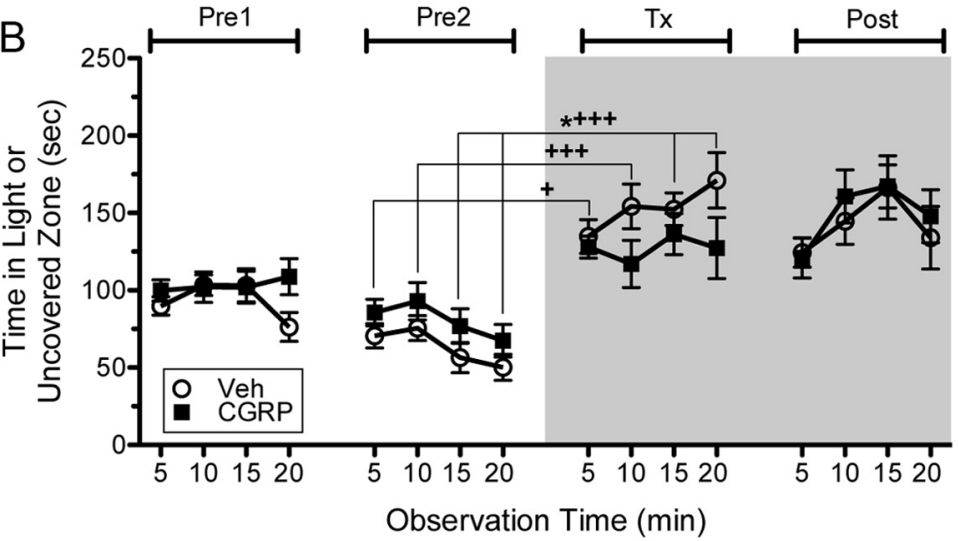

Figure 4. CGRP-induced aversion is dependent on light. $A$, Time spent in uncovered (normally light) zone with lights off ( $\sim 0$ lux) during all four exposures. Mice injected with vehicle (Veh) $(O, n=10)$ or $\operatorname{CGRP}(\boldsymbol{\square}, n=10)$. $\boldsymbol{B}$, Time spent in light zone with lights on $\left(2.7 \times 10^{4}\right.$ lux $)$ or uncovered zone with lights off ( $\sim 0$ lux). Lights were on for first two exposures and off for the last two exposures (Veh, $\bigcirc, n=9$; (GRP, $\mathbf{\square}, n=10)$. After intracerebroventricular injection, CGRP-treated mice compared with vehicle spent similar amount of time in the uncovered zone in both $\boldsymbol{A}$ and $\boldsymbol{B}$. Brackets marked with symbols indicate a significant difference between treatment and either pretreatment 2 or post-treatment (CGRP: ${ }^{*} p<0.05$; Veh: ${ }^{+} p<0.05,{ }^{++} p<0.01,{ }^{++} p<$ 0.01). Error bars indicate mean \pm SEM.

amounts of time in light during the pretreatment exposures. This pattern suggests that CGRP-induced light aversion is unmasked when novelty of the chamber is reduced due to pre-exposure to the chambers and after the mice have explored the box for the initial $5 \mathrm{~min}$ interval. Similar behavior was seen with both sexes. In post-treatment, both the vehicle and CGRP groups spent a comparable amount of time in light. CGRP-treated mice spent significantly more time in the light in post-treatment compared with the previous exposure at 10,15 , and 20 min intervals ( $p<$ 0.001 ) returning to pretreatment levels. Thus, the combination of bright light and repeated testing was required to observe a difference between treatments groups, and the CGRP-induced light aversion was reversible.

As a secondary measure of light avoidance behavior, we analyzed the number of transitions between the light and dark zones. Overall, the pattern of behavior parallels the time in light observations (Fig. 3B). Both treatment groups had a comparable number of transitions during pretreatment exposures. After treatment, there was a overall effect of treatment $\left(F_{(1,33)} 6.18 ; p=\right.$ 0.018); CGRP-treated mice transitioned less than vehicle-treated mice at 15 and 20 min intervals $(p<0.01)$. Compared with pretreatment exposures, CGRP-treated mice transitioned less at 10,15 , and 20 min intervals $(p<0.01)$. In post-treatment, the number of transitions was similar in both treatment groups and returned to similar pretreatment behavior. CGRP-treated mice transitioned more in post-treatment than during the treatment exposure at 5,15 , and $20 \mathrm{~min}(p<0.001)$. Therefore, as seen with time in light, CGRP induced a significant decrease in the number of transitions.

\section{Light dependence of CGRP-induced aversive behavior}

Two dark control experiments were performed to confirm that CGRP-induced avoidance behavior was light dependent. This was of particular concern, since the dark zone was covered while the light zone was uncovered. Therefore, it remained unknown if the uncovered nature of the light zone could be an aversive condition. In the first control, the mice were tested with all lights off so that both zones were dark. In this paradigm, the former light and dark zones are referred to as the uncovered and covered zones, respectively. During all exposures, including following treatment, the vehicle and CGRP cohorts spent comparable time in the uncovered zone (Fig. 4A). Moreover, CGRP-treated mice did not decrease the amount of time in the uncovered zone compared with vehicle-treated mice. Note that compared to when the light is on (Fig. 3A), the mice actually spent more time in the uncovered zone when it was dark. This is consistent with our previous study with nestin/ hRAMP1 mice (Recober et al., 2010). Hence, the avoidance observed in the lightdark box following CGRP-treatment appears to be specific to the light and not to other conditions of the uncovered zone.

The second dark control experiment for light dependence was designed to account for any effect of learning during the pretreatment exposures. For this paradigm, lights were left on during the pretreatment exposures to fully mimic the pretreatment training protocol. Then during the treatment and post-treatment exposures, all lights were turned off, so both zones were dark. Under these conditions, neither vehicle nor CGRP decreased time in the uncovered, previously light, zone (Fig. $4 B$ ). Instead, both groups increased the amount of time spent in the uncovered zone compared with the pretreatment exposures in several intervals $(p<$ 0.05 ), reaffirming that the light was innately aversive even before treatment. In the post-treatment exposure, both groups spent similar amounts of time in the uncovered zone. Although the chamber is not novel in the repeated exposure paradigm as observed with the latency data (Fig. $2 B, C$ ), the second dark control experiment indicates that the association of light to the uncovered zone is not learned sufficiently to cause CGRP-induced light aversion in the absence of light. Together, the two dark control experiments demonstrate that the avoidance induced by CGRP is dependent on the presence of light as the aversive condition.

CGRP-induced light aversion unexplained by anxiety alone To assess whether CGRP-induced light aversion was influenced by anxiety, we analyzed center avoidance in an open field. Mice were exposed to the light-dark box twice under identical condi- 
A

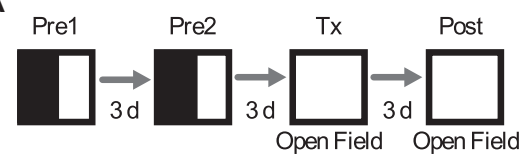

B

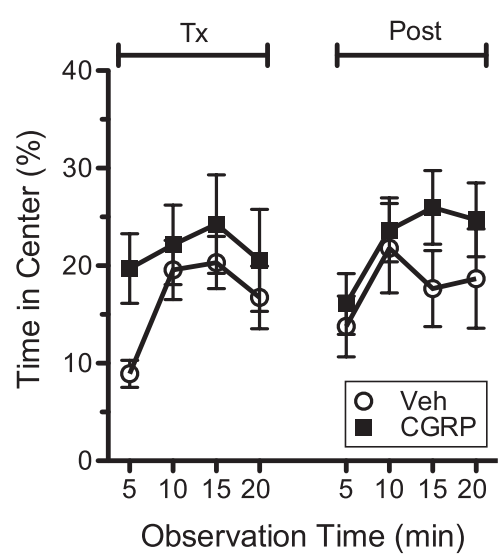

Figure 5. CGRP has no effect on anxiety-like behavior in an open field test. $A$, Schematic of repeated testing paradigm used for the open field test. WT mice were exposed to light-dark box in pretreatment 1 (Pre1) and pretreatment 2 (Pre2) exposures under the same conditions used for the light aversion assay; however, during the treatment (Tx) and post-treatment (Post) exposures the dark insert was removed to create an open field. $\boldsymbol{B}$, Time in center in at $2.7 \times 10^{4}$ lux after intracerebroventricular injection of $\operatorname{GRP}(\boldsymbol{\square}, n=10)$ or vehicle (Veh) $(O, n=10)$ during the treatment and post-treatment exposures. There were no significant differences between times spent in the center zone. Error bars indicate mean \pm SEM.

tions as used with the light aversion assay; however, on the third exposure, mice were placed in the chamber without a dark insert, which created an open field (Fig. 5A). Light intensity remained at $2.7 \times 10^{4}$ lux. For post-treatment, the chamber remained an open field. After intracerebroventricular administration of CGRP or vehicle, treatment had no effect on time in the center of the field (Fig. $5 B$ ). In post-treatment, both treatment groups also spent comparable amounts of time in the center. Overall, there were no treatment differences, indicating that CGRP did not enhance anxiety-related behavior in the open field. However, while anxiety alone is not likely to explain CGRP-induced avoidance of light, an anxiogenic contribution is possible.

\section{CGRP caused reduced motility in the dark zone only}

Since exploration is required in the light-aversion assay, we assessed the effect of CGRP on motility as measured by multiple parameters: resting time, distance traveled, ambulatory velocity, and vertical beam breaks. All parameters were normalized to the time spent in each zone, light or dark, to account for the difference in time spent in one zone over the other. Perhaps most striking was the effect of CGRP on resting time in the dark zone (Fig. $6 A$ ). In the dark zone, CGRP-treated mice rested more than vehicle-treated mice at 10,15, and 20 min intervals $(p<0.01, p<$ $0.001, p<0.05$, respectively; overall treatment effect, $F_{(1,33)}=$ $11.51 ; p<0.002)$. In addition, CGRP-treated mice spent more time resting compared with pretreatment and post-treatment $(p<0.001)$. There were no significant differences between groups in the light zone during treatment exposures or in either the dark or the light zone during pretreatment and posttreatment exposures. The increase in resting time was associated with a decrease in ambulation (distance traveled) in the dark for CGRP treatment compared with vehicle at 10 and $15 \mathrm{~min}$ $(p<0.01, p<0.05$, respectively; overall treatment effect, $\left.F_{(1,33)}=7.19 ; p=0.011\right)$ and compared with pretreatment and post-treatment at all time intervals ( $p<0.001)$ (data not shown). Ambulatory velocity was generally unaffected by CGRP treatment (Fig. 6C). Finally, vertical beam breaks, which indicate rearing on the hindpaws, were affected by treatment (overall treatment effect, $\left.F_{(1,33)}=4.28 ; p=0.046\right)$ with CGRP-treated mice reducing vertical activity compared with vehicle at 10 and 15 $\min (p<0.05)$ in the dark zone but not the light (Fig. $6 B$ ). Again, there were no significant differences between the groups during the pretreatment and post-treatment exposures, and CGRPtreated mice reduced vertical activity in the dark compared with pretreatment and post-treatment at 10 and $15 \min (p<0.05)$. Overall, WT mice demonstrated CGRP-induced reduction in motor activity in the dark zone, but were able to move normally in the light zone and velocity was unaffected in both zones suggesting that altered locomotion alone cannot account for a preference for the dark zone.

\section{Coadministration of rizatriptan-attenuated CGRP-induced light aversion}

We then asked whether the light-aversive actions of CGRP could be attenuated by coadministration of a triptan drug, rizatriptan. The triptans are $5-\mathrm{HT}_{1 \mathrm{~B} / \mathrm{D}}$ agonists that are widely used for treating migraine (Goadsby et al., 2002). For this study, there were four treatment groups with agents given in a single intracerebroventricular injection: (1) vehicle, (2) CGRP, (3) CGRP and rizatriptan, and (4) rizatriptan alone. In the treatment exposure, treatment had an overall effect $\left(F_{(3,83)}=3.83 ; p<0.02\right)$ (Fig. $7 A$ ). Coadministration of rizatriptan with CGRP attenuated the CGRP-induced light avoidance, such that there was no significant difference with vehicle treatment in all four intervals. Moreover, in secondary analysis, mice coadministered CGRP and rizatriptan spent more time in light at 15 and $20 \mathrm{~min}(p<0.05)$ than CGRP only-treated mice when only those two groups were included in ANOVA (overall treatment effect, $F_{(1,46)}=5.89, p<$ 0.02 ). As observed earlier, CGRP decreased time in the light compared with pretreatment $(p<0.05)$. CGRP had a significant effect compared with vehicle and rizatriptan alone at $15 \mathrm{~min}(p<$ $0.01, p<0.05$, respectively). There was no significant effect of rizatriptan alone compared with vehicle. All mice demonstrated the same behavior in pretreatment and post-treatment exposures. In conclusion, coadministration of rizatriptan attenuated CGRP-induced light aversion.

Rizatriptan reduced CGRP effects on transitions and motility As seen with time in the light, cotreatment with rizatriptan attenuated the CGRP-induced decrease in transitions (Fig. 7B). There was no significant difference compared with vehicle treatment. As seen before, treatment with CGRP had an overall effect $\left(F_{(3,83)}=4.05 ; p=0.01\right)$, with fewer transitions than vehicle and rizatriptan at 15 and $20 \mathrm{~min}(p<0.05)$.

With respect to motility parameters, rizatriptan reduced CGRP effects, with an overall treatment effect in the dark zone on resting time $\left(F_{(3,83)}=8.03 ; p<0.0001\right)$ (Fig. $\left.8 A\right)$ and ambulatory distance $\left(F_{(3,83)}=5.64 ; p=0.001\right)$ (data not shown). In the dark zone, rizatriptan coadministered with CGRP blocked CGRPinduced increase in resting time at $20 \mathrm{~min}(p<0.01)$. Similar trends were found with vertical activity (Fig. $8 B$ ). For all motility parameters, all treatment groups behaved similarly in the light zone except that CGRP-treated mice broke fewer vertical beams than vehicle-treated mice at $20 \mathrm{~min}(p<0.001)$ (Fig. 8). Rizatriptan on its own generally had no significant effect on any of the parameters. In combination, these data suggest rizatriptan not only attenuates CGRP-induced light aversion, but also dimin- 
A

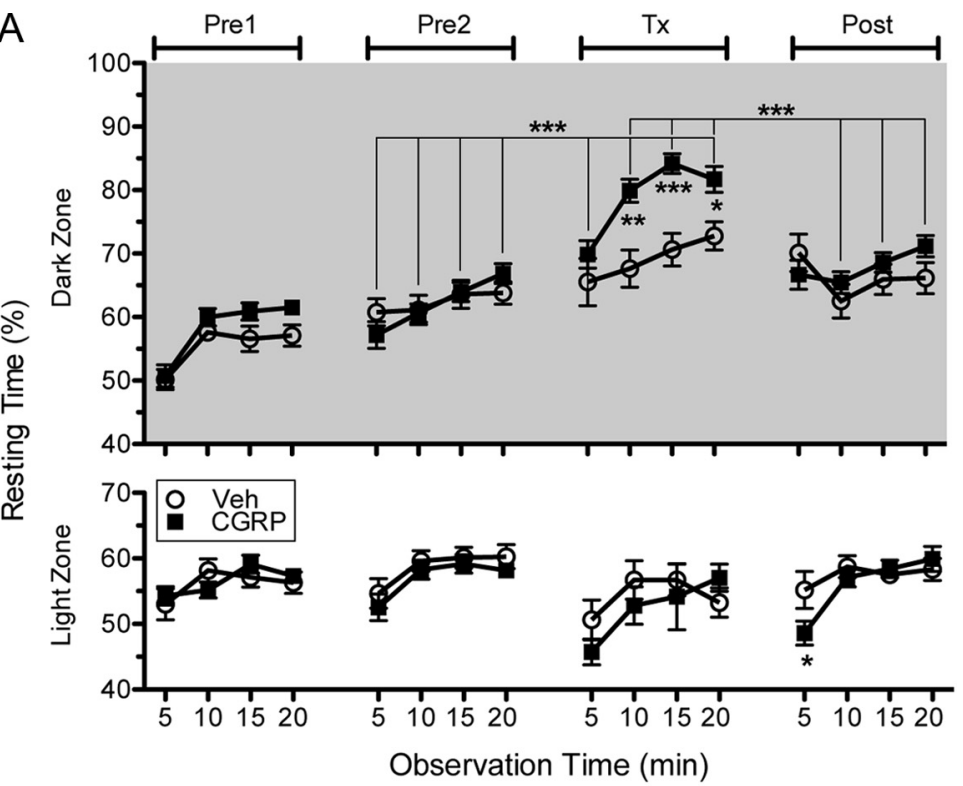

B

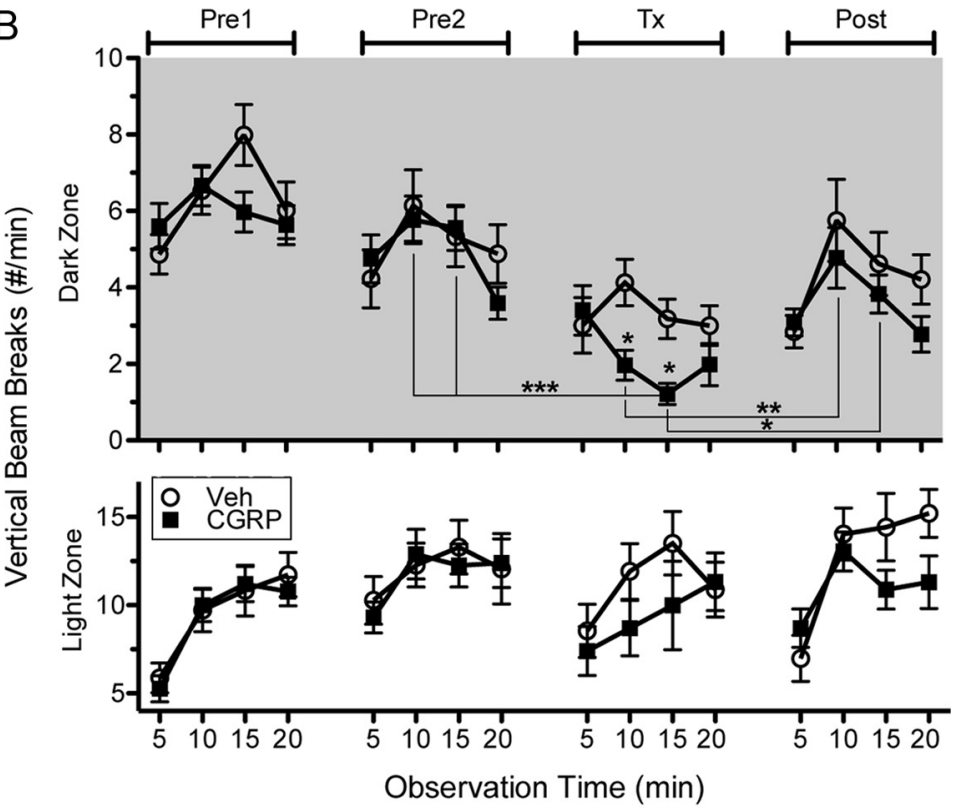

C
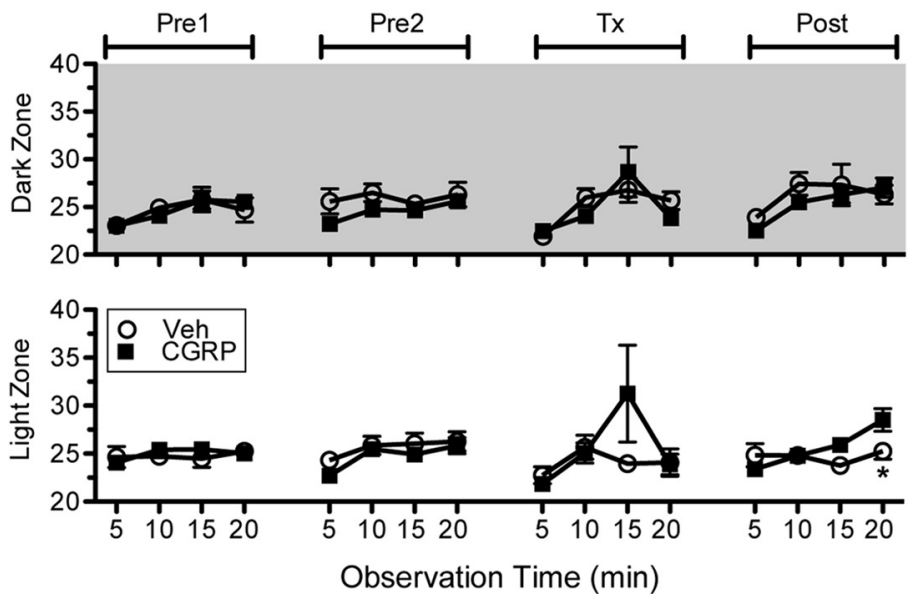

Figure 6. CGRP decreases motility in the dark zone. A, Amount of time resting by WT mice during four repeated exposures to the light-dark box at $2.7 \times 10^{4}$ lux. After intracerebroventricular injection, CGRP-treated $(\square, n=20)$ mice compared with vehicle (Veh) $(\bigcirc, n=15)$ rested more $\left({ }^{*} p<0.05,{ }^{* *} p<0.01,{ }^{* * *} p<0.001\right)$ in the dark zone at indicated intervals. In post-treatment CGRP-treated mice also rested more than vehicle-treated mice in the light zone only $\left({ }^{*} p<0.05\right)$. CGRP-treated mice also rested ishes CGRP-induced effects on exploration and locomotion in the dark.

\section{Discussion}

In this study, we have established that CGRP can induce light-aversive behavior in WT mice. This builds on our previous finding of CGRP-induced light aversion in nestin/hRAMP1 transgenic mice that are sensitized to CGRP (Recober et al., 2009, 2010). Importantly, the light-avoidance behavior of WT mice demonstrates that endogenous CGRP receptors are sufficient to transduce light aversion. This suggests that the behavior of nestin/ $h R A M P 1$ mice is not due to ectopic receptor expression, but instead reflects enhanced signaling of endogenous receptors. Moreover, the efficacy of rizatriptan in this study supports the prediction that CGRP-induced light aversion may be analogous to photophobia experienced during migraine.

To reveal CGRP-sensitivity of WT mice, it was necessary to use a combination of increased light intensity and habituation to the light-dark box. The inability of low light to induce light aversion in WT mice is consistent with previous observations with control littermates (Recober et al., 2009, 2010). However, increasing the light intensity to a level similar to direct daylight led to only a minimal degree of light aversion. Instead, the combination of prior exposure of WT mice to the chamber along with higher light was required. It should be noted that the procedure did not induce a conditioned place aversion in which mice learn to associate one chamber with an aversive stimulus (King et al., 2009), since CGRP-treated mice recovered similarly to mice given vehicle. This also indicates that CGRP actions were reversible and not sustained. Furthermore, in the dark control with lights on during the first two exposures,

$$
\leftarrow
$$

more compared with pretreatment and post-treatment $\left({ }^{* * *} p<0.001\right)$ as indicated by brackets. $\boldsymbol{B}$, Vertical beam breaks, a measure of rearing, by WT mice during four repeated exposures to the light-dark box at $2.7 \times 10^{4}$ lux. After intracerebroventricular injection, CGRP-treated $(\boldsymbol{\square}, n=20)$ mice compared with vehicle (Veh) $(\bigcirc, n=15)$ reared less $\left({ }^{*} p<\right.$ $0.05)$ in the dark zone at indicated intervals. CGRP-treated mice also reared less compared with pretreatment and posttreatment $\left({ }^{*} p<0.05,{ }^{* *} p<0.01,{ }^{* * *} p<0.001\right)$ as indicated by brackets. $C$, Ambulatory velocity of WT mice during four repeated exposures to the light- dark box at $2.7 \times 10^{4}$ lux. After intracerebroventricular injection, CGRP-treated $(\boldsymbol{\square}$, $n=20)$ mice compared with vehicle (Veh) $(\bigcirc, n=15)$ were similar. In post-treatment, vehicle-treated mice moved at lower velocity than (GRP-treated mice at the 20 min interval $\left({ }^{*} p<0.05\right)$. Error bars indicate mean \pm SEM. 
the prior exposure was insufficient to form a negative association with the light zone. A key control was that CGRP effects were dependent on the presence of light. With the lights off, CGRP-treated mice behaved like vehicle-treated mice. In fact, the mice showed a slight preference for the uncovered zone when the light was off, which agrees with other studies (Bourin and Hascoët, 2003; Recober et al., 2010; Semo et al., 2010). In conclusion, this paradigm unveiled reversible CGRP-induced light aversion in WT mice.

Relatively few studies with rodents in a light-dark box have addressed photophobia. In addition to previously mentioned studies with nestin/hRAMP1 mice, Thiels et al. (2008) showed that albino mice were more sensitive to light than C57BL/6J mice. In a study addressing photophobia mechanisms, Thompson et al. (2010) found that mice lacking nonimage-forming irradiance detection (Rpe65 ${ }^{-/-}$and $r d 1$ mice) were no longer light aversive, suggesting that melanopsin retinal ganglion cells (mRGCs) drive this behavior. In this context, mRGCs have been shown to be sufficient, but not required for light aversion by mice (Semo et al., 2010). mRGCs are thought to play a critical role in mediating photophobia in humans (Noseda et al., 2010; La Morgia et al., 2011; Noseda and Burstein, 2011). Recently, the Helyes group used the light-dark box to demonstrate that nitroglycerin, which can induce migraine in people (Juhasz et al., 2003), also induced light avoidance in WT mice (Markovics et al., 2012). Overall, these studies describe light aversion due to innate or induced light sensitivity that likely illustrate behavior consistent with photophobia.

In addition to measuring light-aversive behavior, we were able to simultaneously collect information on transitions and motility. While transitions have been used as an indicator of anxiety level, they do not necessarily correlate with time in light (Bourin and Hascoët, 2003). In both this study and our previous study with nestin/hRAMP1 mice, decreased transitions did correlate with decreased time in light (Recober et al., 2010). Only two studies have previously compared locomotion in the light and dark zones of the boxes (Takao and Miyakawa, 2006; Recober et al., 2010). As observed with nestin/hRAMP1 mice (Recober et al., 2010), motility of WT mice was reduced by CGRP treatment only in the dark zone. This was manifested as an increase in resting time with a compensatory decrease in distance traveled, as well as decreased vertical activity. We surmise that CGRP is aggravating nociception upon movement, which may correspond to pain aggravation by routine activity, a diagnostic criterion of migraine (Headache Subcommittee of the International Headache Society, 2004). Since this occurred only in the dark zone, we speculate that the mice are moving to avoid the light until they are in the dark zone, where they rest. Furthermore, CGRP did not affect ambulatory velocity in either zone. While we cannot completely elim- inate reduced locomotion as a potential confounder, it is clear that CGRP-treated mice were capable of ambulating, and reduction of motor activity only occurred in the dark.

We used the open field assay to demonstrate that intracerebroventricular administration of CGRP does not increase anxiogenic behavior. This is in agreement with our previous findings with nestin/hRAMP1 mice (Recober et al., 2009). The open field results suggest that anxiety alone does not explain CGRP-induced lightaversive behavior. However, we want to emphasize that this result does not rule out an anxiety component to the light-aversive behavior, especially given the close association of aversive and anxiogenic behaviors in the light-dark assay (Bourin and Hascoët, 2003). Indeed, we observed that CGRP treatment increased the speed of the freezing response of both nestin/hRAMP1 and control littermates to a predator odor (Recober et al., 2009), and injection of CGRP into the bed nucleus stria terminalis has been reported to increase anxiogenic behaviors (Sink et al., 2011). In this regard, the abundance of CGRP fibers and receptors in the amygdala and nearby areas associated with emotional reactions could potentially contribute to the light aversion (Raddant and Russo, 2011).

Our findings raise the question of how CGRP triggers light aversion. The intracerebroventricular administration route indi- 
A

A

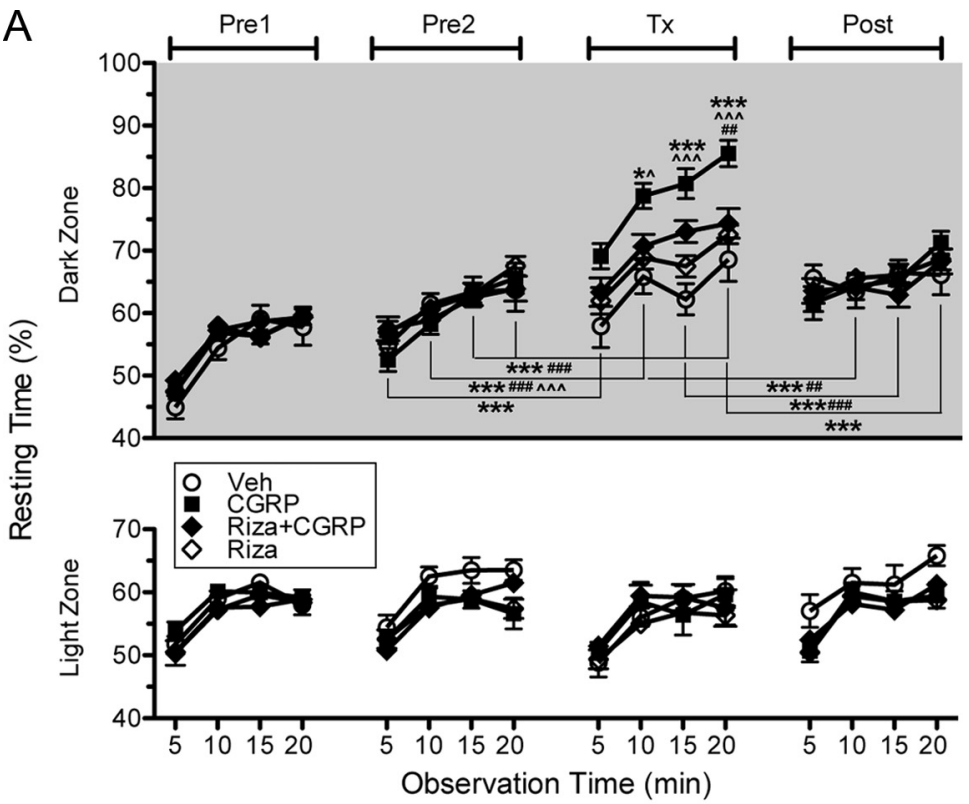

B

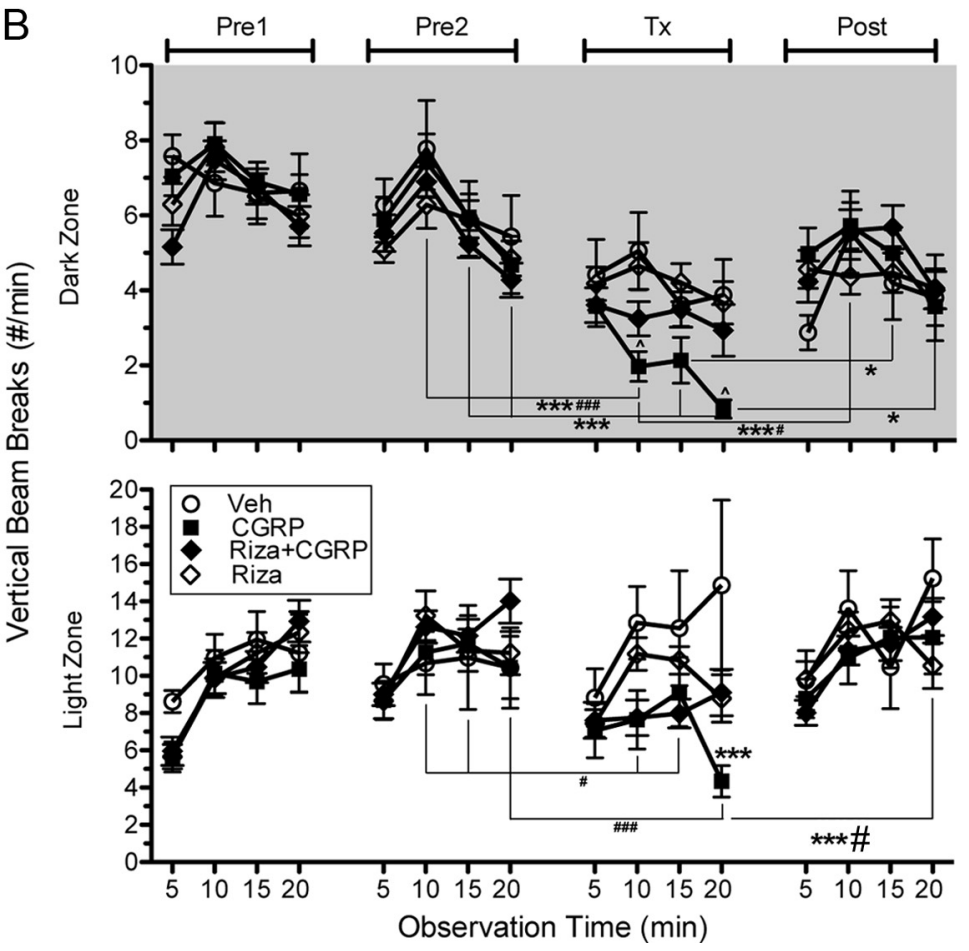

Figure 8. Rizatriptan reduces (GRP effects on transitions and motility. $\boldsymbol{A}$, Time resting and ( $\boldsymbol{B}$ ) vertical activity during four repeated exposures to the light- dark box at $2.7 \times 10^{4}$ lux. After intracerebroventricular injection, CGRP-treated $(\boldsymbol{\square}, n=19)$ mice compared with vehicle (Veh) $(O, n=10)\left({ }^{*} p<0.05,{ }^{* * *} p<0.01\right)$, coadministration of rizatriptan (Riza) and CGRP ( $n=29)\left({ }^{\# \#} p<0.01\right)$, and rizatriptan alone $(\diamond, n=29)\left(\wedge_{p}<0.05, \wedge^{\wedge} \wedge_{p}<0.001\right)$ at indicated intervals. Brackets marked with symbols indicate a significant difference between treatment and either pretreatment 2 or post-treatment (GRP: ${ }^{*} p<0.05$, ${ }^{* * *} p<0.001$; Riza + CGRP: ${ }^{\#} p<0.05,{ }^{\# \# p} p<0.01,{ }^{\# \#} p<0.001$; Riza: $\left.\wedge^{\wedge} \wedge_{p}<0.001\right)$. For resting time in the light zone rizatriptan- and vehicle-treated mice were different $\left({ }^{\neq} p<0.05\right)$ in post-treatment at the 5 min interval. Error bars indicate mean \pm SEM.

cates that CGRP is acting centrally; however, since some extracranial leakage occurs during injection, we cannot rule out peripheral sites of action. Nonetheless, systemic effects of leakage are not likely to be appreciable (Nikai et al., 2008). Focusing on central actions, one possibility is that CGRP acts as a neuromodulator to increase the activity of light-sensitive neurons. For instance, CGRP has been shown to increase glutamate receptor activity (Ebersberger et al., 2000; Gu and $\mathrm{Yu}, 2007)$. In this scenario, ordinarily non-noxious light stimuli would be enhanced by CGRP neuromodulation to supersede a pain threshold (Ho et al., 2010; Raddant and Russo, 2011). One likely site of CGRP action could be the posterior thalamus and nearby nuclei, where Burstein et al. (Noseda et al., 2010) demonstrated a convergence of signals from dura- and light-sensitive neurons. CGRP receptors have been identified near this region (Summ et al., 2010). Hence, CGRP could potentially enhance glutaminergic synaptic transmission in the thalamus from third-order trigeminovascular nociceptive and light-activated mRGC neurons. This scenario might also invoke CGRP fibers that project from the thalamus to the amygdala and are thought to play roles in behavioral responses to somatosensory stimuli (Yasui et al., 1991; D'Hanis et al., 2007). Another likely site of action of CGRP is at receptors in the spinal trigeminal nucleus, where Bereiter et al. (Okamoto et al., 2009, 2010) have shown neuronal activation by bright light. Future studies will be needed to address whether the trigeminovascular pathway is activated under the conditions used in our study, as proposed in migraine photophobia (Noseda and Burstein, 2011). Targeted regulation of CGRP receptor activity should help reveal which of these sites play a role in photophobia.

A key finding of this study is that rizatriptan, a common anti-migraine drug, attenuated CGRP-induced light aversion. Rizatriptan limited both the decrease in time in light and number of transitions, as well as blocking the increased resting time and corresponding decreased vertical activity and distance traveled. Triptan actions at $5-\mathrm{HT}_{1 \mathrm{D}}$ receptors are known to inhibit neuropeptide release, including CGRP (Durham and Russo, 2002; Loder, 2010). Yet, triptans are known to have other roles beyond inhibiting CGRP release. Via $5-\mathrm{HT}_{1 \mathrm{~B}}$ receptors, triptans cause vasoconstriction, and clinical studies have demonstrated triptans can reverse CGRPinduced vasodilation (Asghar et al., 2010, 2011). Importantly, triptans can also reduce CGRP-induced headache pain (Asghar et al., 2011). Both 5-HT 1 and CGRP immunoreactivity are colocalized in the spinal trigeminal nucleus and other areas in the brainstem (Noseda et al., 2008), and triptans can downregulate nociceptive signal transmission in the spinal trigeminal nucleus (Mitsikostas et al., 1999; Levy et al., 2004). These observations support our finding that triptans can supersede or minimize the effects of a bolus injection of CGRP in the brain. Wherever the site of action, triptan efficacy in our model likely results from actions at multi- 
ple sites, as proposed for their ability to treat migraine (Ahn and Basbaum, 2005).

In conclusion, our study demonstrates for the first time that signaling from endogenous CGRP receptors is sufficient to trigger a light-aversive response. The ability of rizatriptan to overcome the effects of CGRP in mice mimics what has been observed in humans and provides insight into the relationship between CGRP and triptans. Consequently, this system provides a functional platform for identifying neural pathways responsible for light aversion and preclinical testing of candidate agents to ameliorate photophobia in migraine.

\section{References}

Ahn AH, Basbaum AI (2005) Where do triptans act in the treatment of migraine? Pain 115:1-4. CrossRef Medline

Amrutkar DV, Ploug KB, Hay-Schmidt A, Porreca F, Olesen J, Jansen-Olesen I (2012) mRNA expression of 5-hydroxytryptamine 1B, 1D, and $1 \mathrm{~F}$ receptors and their role in controlling the release of calcitonin gene-related peptide in the rat trigeminovascular system. Pain 153:830-838. CrossRef Medline

Arulmani U, Maassenvandenbrink A, Villalón CM, Saxena PR (2004) Calcitonin gene-related peptide and its role in migraine pathophysiology. Eur J Pharmacol 500:315-330. CrossRef Medline

Asghar MS, Hansen AE, Kapijimpanga T, van der Geest RJ, van der Koning P, Larsson HB, Olesen J, Ashina M (2010) Dilation by CGRP of middle meningeal artery and reversal by sumatriptan in normal volunteers. Neurology 75:1520-1526. CrossRef Medline

Asghar MS, Hansen AE, Amin FM, van der Geest RJ, Koning P, Larsson HB, Olesen J, Ashina M (2011) Evidence for a vascular factor in migraine. Ann Neurol 69:635-645. CrossRef Medline

Ashby R, Ohlendorf A, Schaeffel F (2009) The effect of ambient illuminance on the development of deprivation myopia in chicks. Invest Ophthalmol Vis Sci 50:5348-5354. CrossRef Medline

Borsook D, Burstein R, Moulton E, Becerra L (2006) Functional imaging of the trigeminal system: applications to migraine pathophysiology. Headache 46 [Suppl 1]:S32-S38.

Bourin M, Hascoët M (2003) The mouse light/dark box test. Eur J Pharmacol 463:55-65. CrossRef Medline

Cady RK, Vause CV, Ho TW, Bigal ME, Durham PL (2009) Elevated saliva calcitonin gene-related peptide levels during acute migraine predict therapeutic response to rizatriptan. Headache 49:1258-1266. CrossRef Medline

Crawley JN (2008) Behavioral phenotyping strategies for mutant mice. Neuron 57:809-818. CrossRef Medline

D’Hanis W, Linke R, Yilmazer-Hanke DM (2007) Topography of thalamic and parabrachial calcitonin gene-related peptide (CGRP) immunoreactive neurons projecting to subnuclei of the amygdala and extended amygdala. J Comp Neurol 505:268-291. CrossRef Medline

Drummond PD, Woodhouse A (1993) Painful stimulation of the forehead increases photophobia in migraine sufferers. Cephalalgia 13:321-324. CrossRef Medline

Durham PL, Russo AF (2002) New insights into the molecular actions of serotonergic antimigraine drugs. Pharmacol Ther 94:77-92. CrossRef Medline

Ebersberger A, Charbel Issa P, Vanegas H, Schaible HG (2000) Differential effects of calcitonin gene-related peptide and calcitonin gene-related peptide 8-37 upon responses to N-methyl-D-aspartate or (R, S)-alphaamino-3-hydroxy-5-methylisoxazole-4-propionate in spinal nociceptive neurons with knee joint input in the rat. Neuroscience 99:171-178. CrossRef Medline

Gaskill BN, Gordon CJ, Pajor EA, Lucas JR, Davis JK, Garner JP (2012) Heat or insulation: behavioral titration of mouse preference for warmth or access to a nest. PLoS One 7:e32799. CrossRef Medline

Goadsby PJ (2009) Pathophysiology of migraine. Neurol Clin 27:335-360. CrossRef Medline

Goadsby PJ, Edvinsson L (1993) The trigeminovascular system and migraine: studies characterizing cerebrovascular and neuropeptide changes seen in humans and cats. Ann Neurol 33:48-56. CrossRef Medline

Goadsby PJ, Lipton RB, Ferrari MD (2002) Migraine-current understanding and treatment. N Engl J Med 346:257-270. CrossRef Medline

Gu XL, Yu LC (2007) The colocalization of CGRP receptor and AMPA re- ceptor in the spinal dorsal horn neuron of rat: a morphological and electrophysiological study. Neurosci Lett 414:237-241. CrossRef Medline

Hansen JM, Hauge AW, Olesen J, Ashina M (2010) Calcitonin gene-related peptide triggers migraine-like attacks in patients with migraine with aura. Cephalalgia 30:1179-1186. CrossRef Medline

Headache Subcommittee of the International Headache Society (2004) The international classification of headache disorders: 2 nd edition. Cephalalgia 24 [Suppl 1]:9-160.

Ho TW, Mannix LK, Fan X, Assaid C, Furtek C, Jones CJ, Lines CR, Rapoport AM (2008) Randomized controlled trial of an oral CGRP receptor antagonist, MK-0974, in acute treatment of migraine. Neurology 70:13041312. CrossRef Medline

Ho TW, Edvinsson L, Goadsby PJ (2010) CGRP and its receptors provide new insights into migraine pathophysiology. Nat Rev Neurol 6:573-582. CrossRef Medline

Juhasz G, Zsombok T, Modos EA, Olajos S, Jakab B, Nemeth J, Szolcsanyi J, Vitrai J, Bagdy G (2003) NO-induced migraine attack: strong increase in plasma calcitonin gene-related peptide (CGRP) concentration and negative correlation with platelet serotonin release. Pain 106:461-470. CrossRef Medline

Juhasz G, Zsombok T, Jakab B, Nemeth J, Szolcsanyi J, Bagdy G (2005) Sumatriptan causes parallel decrease in plasma calcitonin gene-related peptide (CGRP) concentration and migraine headache during nitroglycerin induced migraine attack. Cephalalgia 25:179-183. CrossRef Medline

King T, Vera-Portocarrero L, Gutierrez T, Vanderah TW, Dussor G, Lai J, Fields HL, Porreca F (2009) Unmasking the tonic-aversive state in neuropathic pain. Nat Neurosci 12:1364-1366. CrossRef Medline

La Morgia C, Ross-Cisneros FN, Hannibal J, Montagna P, Sadun AA, Carelli V (2011) Melanopsin-expressing retinal ganglion cells: implications for human diseases. Vision Res 51:296-302. CrossRef Medline

Lassen LH, Haderslev PA, Jacobsen VB, Iversen HK, Sperling B, Olesen J (2002) CGRP may play a causative role in migraine. Cephalalgia 22:5461. CrossRef Medline

Levy D, Jakubowski M, Burstein R (2004) Disruption of communication between peripheral and central trigeminovascular neurons mediates the antimigraine action of 5HT 1B/1D receptor agonists. Proc Natl Acad Sci U S A 101:4274-4279. CrossRef Medline

Lipton RB, Bigal ME, Diamond M, Freitag F, Reed ML, Stewart WF (2007) Migraine prevalence, disease burden, and the need for preventive therapy. Neurology 68:343-349. CrossRef Medline

Loder E (2010) Triptan therapy in migraine. N Engl J Med 363:63-70. CrossRef Medline

Markovics A, Kormos V, Gaszner B, Lashgarara A, Szoke E, Sandor K, Szabadfi K, Tuka B, Tajti J, Szolcsanyi J, Pinter E, Hashimoto H, Kun J, Reglodi D, Helyes Z (2012) Pituitary adenylate cyclase-activating polypeptide plays a key role in nitroglycerol-induced trigeminovascular activation in mice. Neurobiol Dis 45:633-644. CrossRef Medline

Messlinger K (2009) Migraine: where and how does the pain originate? Exp Brain Res 196:179-193. CrossRef Medline

Mitsikostas DD, Sanchez del Rio M, Moskowitz MA, Waeber C (1999) Both 5-HT1B and 5-HT1F receptors modulate c-fos expression within rat trigeminal nucleus caudalis. Eur J Pharmacol 369:271-277. CrossRef Medline

Nikai T, Basbaum AI, Ahn AH (2008) Profound reduction of somatic and visceral pain in mice by intrathecal administration of the anti-migraine drug, sumatriptan. Pain 139:533-540. CrossRef Medline

Noseda R, Burstein R (2011) Advances in understanding the mechanisms of migraine-type photophobia. Curr Opin Neurol 24:197-202. CrossRef Medline

Noseda R, Monconduit L, Constandil L, Chalus M, Villanueva L (2008) Central nervous system networks involved in the processing of meningeal and cutaneous inputs from the ophthalmic branch of the trigeminal nerve in the rat. Cephalalgia 28:813-824. CrossRef Medline

Noseda R, Kainz V, Jakubowski M, Gooley JJ, Saper CB, Digre K, Burstein R (2010) A neural mechanism for exacerbation of headache by light. Nat Neurosci 13:239-245. CrossRef Medline

Okamoto K, Thompson R, Tashiro A, Chang Z, Bereiter DA (2009) Bright light produces Fos-positive neurons in caudal trigeminal brainstem. Neuroscience 160:858-864. CrossRef Medline

Okamoto K, Tashiro A, Chang Z, Bereiter DA (2010) Bright light activates a trigeminal nociceptive pathway. Pain 149:235-242. CrossRef Medline

Olesen J, Diener HC, Husstedt IW, Goadsby PJ, Hall D, Meier U, Pollentier S, 
Lesko LM (2004) Calcitonin gene-related peptide receptor antagonist BIBN 4096 BS for the acute treatment of migraine. N Engl J Med 350: 1104-1110. CrossRef Medline

Petersen KA, Lassen LH, Birk S, Lesko L, Olesen J (2005) BIBN4096BS antagonizes human alpha-calcitonin gene related peptide-induced headache and extracerebral artery dilatation. Clin Pharmacol Ther 77:202213. CrossRef Medline

Raddant AC, Russo AF (2011) Calcitonin gene-related peptide in migraine: intersection of peripheral inflammation and central modulation. Expert Rev Mol Med 13:e36. CrossRef Medline

Rasmussen BK, Jensen R, Olesen J (1991) A population-based analysis of the diagnostic criteria of the International Headache Society. Cephalalgia 11: 129-134. CrossRef Medline

Recober A, Russo AF (2009) Calcitonin gene-related peptide: an update on the biology. Curr Opin Neurol 22:241-246. CrossRef Medline

Recober A, Kuburas A, Zhang Z, Wemmie JA, Anderson MG, Russo AF (2009) Role of calcitonin gene-related peptide in light-aversive behavior: implications for migraine. J Neurosci 29:8798-8804. CrossRef Medline

Recober A, Kaiser EA, Kuburas A, Russo AF (2010) Induction of multiple photophobic behaviors in a transgenic mouse sensitized to CGRP. Neuropharmacology 58:156-165. CrossRef Medline

Russell MB, Rasmussen BK, Fenger K, Olesen J (1996) Migraine without aura and migraine with aura are distinct clinical entities: a study of four hundred and eighty-four male and female migraineurs from the general population. Cephalalgia 16:239-245. CrossRef Medline

Semo M, Gias C, Ahmado A, Sugano E, Allen AE, Lawrence JM, Tomita H, Coffey PJ, Vugler AA (2010) Dissecting a role for melanopsin in behav- ioural light aversion reveals a response independent of conventional photoreception. PLoS One 5:e15009. CrossRef Medline

Sink KS, Walker DL, Yang Y, Davis M (2011) Calcitonin gene-related peptide in the bed nucleus of the stria terminalis produces an anxiety-like pattern of behavior and increases neural activation in anxiety-related structures. J Neurosci 31:1802-1810. CrossRef Medline

Summ O, Charbit AR, Andreou AP, Goadsby PJ (2010) Modulation of nocioceptive transmission with calcitonin gene-related peptide receptor antagonists in the thalamus. Brain 133:2540-2548. CrossRef Medline

Takao K, Miyakawa T (2006) Light/dark transition test for mice. J Vis Exp 13:104.

Tfelt-Hansen P, Le H (2009) Calcitonin gene-related peptide in blood: is it increased in the external jugular vein during migraine and cluster headache? A review. J Headache Pain 10:137-143. CrossRef Medline

Thiels E, Hoffman EK, Gorin MB (2008) A reliable behavioral assay for the assessment of sustained photophobia in mice. Curr Eye Res 33: 483-491. CrossRef Medline

Thompson S, Recober A, Vogel TW, Kuburas A, Owens JA, Sheffield VC, Russo AF, Stone EM (2010) Light aversion in mice depends on nonimage-forming irradiance detection. Behav Neurosci 124:821827. CrossRef Medline

van Rossum D, Hanisch UK, Quirion R (1997) Neuroanatomical localization, pharmacological characterization and functions of CGRP, related peptides and their receptors. Neurosci Biobehav Rev 21:649-678. CrossRef Medline

Yasui Y, Saper CB, Cechetto DF (1991) Calcitonin gene-related peptide (CGRP) immunoreactive projections from the thalamus to the striatum and amygdala in the rat. J Comp Neurol 308:293-310. CrossRef Medline 